\title{
REGIONAL HUMAN CAPITAL MANAGEMENT - ASPECTS OF INTERACTION WITH THE ECONOMIC DEVELOPMENT OF THE TERRITORY
}

\author{
Georgi Nikolov ${ }^{1}$ \\ Elka Vasileva ${ }^{2}$ \\ Veselina Lyubomirova ${ }^{3}$
}

DOI: https://doi.org/10.31410/LIMEN.2020.253

\begin{abstract}
The development and modernization of societies define new approaches in managing human resources and, in particular, their characteristic-human capital. There is a growing need for its study and characterization and analysis of the extent to which it is crucial for the economic development of European regions, particularly Bulgaria. Human capital is a specific public resource phenomenon that creates added value based on education, knowledge, skills, intelligence, acquired professional experience, and many other components. The object of study is the targeted promotion of these components through public policies, programs, and initiatives, which creates prerequisites for improving the regions' overall economic performance. The authors set the task to analyze the stated public policies presented in the integrated territorial strategies to develop the planning regions, emphasizing the specific dimensions of human capital management in the different territories.
\end{abstract}

Keywords: Human capital, Planning regions, Integrated territorial strategy.

\section{INTRODUCTION}

$\mathrm{H}$ uman capital formation is a complex and lengthy process that must be managed following public policy principles aimed at human resources. People must be able to withstand the challenges of the present and, at the same time, become a decisive factor for the economic prosperity of the country. The need to define the terms "human capital" and "human resources" is dictated by their particular importance for socio-economic development. In the process of integration and membership of Bulgaria in the European Union, in the conditions of globalization, these circumstances become more and more critical for the realization of strategy and policy of catching up economic development (Angelov, 2003).

The relationship between human capital, human resources, and economic development is complex and interdependent. Investments in human capital are fundamental and decisive for the directions and dynamics of human resources development. Investments in human capital should be the subject of a long-term government policy that reflects the government's economic growth intentions in the medium and long term.

An essential condition is that the interventions focus on education, healthcare, science, culture, and personal development, which have the most direct participation in human capital formation.

University of National and World Economy, Sofia, Bulgaria

University of National and World Economy, Sofia, Bulgaria

University of National and World Economy, Sofia, Bulgaria 
The policy for stimulating human capital must be continuously updated, given the growing challenges affecting the living and business environment in different countries' regions. Given the focus of government policy on overcoming harmful disparities in regional development, issues related to the development of appropriate mechanisms and tools to support regional human capital improvement are becoming part of society's current agenda.

Human capital is a specific public resource phenomenon that creates added value based on education, knowledge, skills, intelligence, acquired professional experience, and several other components. The object of study is the targeted promotion of these components through public policies, programs, and initiatives, which creates prerequisites for improving the regions' overall economic performance. The authors set the task to analyze the stated public policies presented in the integrated territorial strategies to develop the planning regions, emphasizing the specific dimensions of human capital management in the different territories. The research's methodological tools include using a systematic method, a formal-logical and deductive method, and an analysis of the content of publicly available literature. Their integrated usage analyzes and evaluates the human capital defining components following the general theoretical, methodological, and normative statement.

\section{THEORETICAL DEFINITION OF HUMAN CAPITAL IN THE CONTEXT OF REGIONAL DEVELOPMENT}

The category "human capital" is the subject of study by various scientific fields and schools. With the complication of social and economic reality, globalization, the transition to industrial and digital development, the interest in its utilization and improvement will continue to grow. In scientific theory, many definitions of the category "human capital" are protected, which, depending on their conceptual task, emphasize one or another of its essential characteristics.

Despite historical sources that the origin of the theory of human capital must be sought in the emergence of classical economic theory in the seventeenth and eighteenth centuries, the idea that we support is that "human capital appeared long before knowledge was has ruled for him."

For the present study, the authors perceive Kazakov's (2010) definition of human capital as "an economic category that is related to a living human person and is the result of investment in knowledge, qualifications and production experience, skills building and other acquisitive properties, which increases the opportunities for work as a factoring service and enriches the properties of the person holding the job function."

Schultz (1961) was the first among economists to define human capital as an additional income source provided by the knowledge, skills, and abilities of the human person, and education as one of the forms of human capital. In this sense, the funds invested by people in education, increasing their professional productivity in working life, in the long run, are treated not as costs but as an investment, the rate of return of which is expressed in more significant employment opportunities and future income. To provide an adequate response to future evermodernizing societies' needs, some human capital development planning is needed. This planning should take place at both the regional and national levels. However, it is impossible to fully anticipate the need for the qualities, skills, and knowledge applicable and needed, even in the nearest future.

As part of human activity, cultural heritage creates real notions of value systems, beliefs, traditions, and lifestyles. The role of state institutions is to develop and implement public 
investment projects to promote regional Culture, build an overall favorable environment and conditions on encouraging private investment, and develop successful public-private partnerships for the country's sector's sustainability (Botseva, Tsolov\&Vasileva, 2020, p.180).

The human capital theory development presupposes the concept's renewal and its connection with many scientific disciplines and categories. One of the strict guidelines for measuring this capital is its manifestation as an individual, company, regional or national and assesses its return in a future moment or period. As a result of the differences in the natural conditions and the degree of development of the human activity in different parts of the countries, they have formed regions with different economic development levels (Tanakov\&Kazakova, 2018, p.515). This calls for the need for regional policy to overcome regional economic imbalances.

\section{CONTEMPORARY ASPECTS OF REGIONAL HUMAN CAPITAL MANAGEMENT}

Significant structural changes in the world economy due to the growing role of scientific and technological progress for economic growth lead to a new approach to human capital analysis.

The focus of developed countries' socio-economic policy at the beginning of the XXI century is increasingly shifting to investing and promoting human capital development. This fact is due to many factors, the main one being the increasingly important role that knowledge and technology play in economies' competitiveness. The investment in human capital itself affects several public sectors, mainly education, training, and science. They largely determine the competitiveness of the workforce and the achievement of sustainable economic growth. Thus, the elucidation of the role of education, health status, and lifestyle in the current permanent trend of globalization of the economy and the decisive penetration of information and communication technologies is usually argued with human capital theory.

The opportunities and challenges for enhanced territorial governance in Bulgaria come to the fore. It is essential to define and understand the government's broader goals for regionalization and the country's path in the long run. Adopting a mechanism to ensure increased involvement at the regional level in the planning and implementation of regional policy actions can strengthen the regional dimension of development efforts. It can also lead to the creation of a critical mass of experts and administrative and technical capacity at the NUTS 2 level, which could pave the way for successful decentralization efforts in the foreseeable future (Nikolov\&Lyubomirova, 2019).

Human capital is a major driving force for the promotion of cultural heritage. Population policies are prepared in the interest of the public good and are designed to mitigate and, if possible, regulate perceived population problems by adapting population size and age structure to people's rights, needs, and aspirations. Good population policies require awareness of the issues involved and a consensus on the actions to be taken (Botseva, 2019, p.612).

The workforce's educational and professional level determines the potential for regional growth regional development management, and it is essential to formulate goals and priorities following each of the region's specific needs and internal potential. A fundamental issue is how the state policy for regional development would support human capital's competitive advantages, a key sector for the regional economy. 
Public institutions need to respond to current and future challenges by building competencies in the following way: hiring new workers, signing temporary services contracts with organizations or individuals, or training the current employees. Human Resource Management in public institutions should rely on human resource practices that provide efficient and effective working. Organizational success and overall work performance depend on employee engagement and discretionary effort. The employees are the most productive when they possess competencies, have access to available resources, proper organizational conditions, and career development opportunities (Chatleska, 2018, p.284).

\section{ANALYSIS OF THE STRATEGIC FRAMEWORK FOR HUMAN CAPITAL DEVELOPMENT IN THE PLANNING REGIONS}

The complex strategic framework, through which the main priorities of the public policies for human capital development are implemented, comprises a package of political documents developed for the period 2021-2027. This paragraph aims to present how the government's intentions to formulate precise mechanisms and tools to support human capital elements are inscribed in its specific regional dimension.

The National Development Program: Bulgaria 2030 occupies a fundamental place, which defines the vision and general goals of development policies in all government sectors, including their territorial dimensions. One of the program's key priorities is to increase the quality of human capital (National Development Program: Bulgaria 2030, p.9) through the formation of highly educated, innovative, and active individuals, able to realize themselves successfully as professionals and citizens. In this way, they are expected to contribute to their well-being and the sustainable development of all social spheres.

Emphasis is placed on improving the health status of the population as a critical determinant of quality of life and as a necessary condition for its inclusion in employment and social activity (National Development Program: Bulgaria 2030, p.38).

In the current planning period for strategic documents, Spatial and Regional Development strongly emphasizes their focus oriented towards "achieving balanced spatial development based on local potential and cohesion of the regions in territorial, economic and social aspects." In this regard, the framework for strategic planning is the Updated National Concept for Spatial Development (2013-2025) and the Integrated Territorial Strategies for Development of Planning Regions (2021-2027) [1].

The National Concept for Spatial Development of Bulgaria, updated in March 2020, retains its role of spatial coordinator of the territory and sectoral policies' processes but pays more attention to the planning regions, to the higher degree of manageability of their development.

The document's analysis as opposing challenges highlighted "demographic stagnation and depopulation, expressed through prolonged population decline and depopulation, depopulation of peripheral areas, the emigration of mostly young and qualified personnel" (Updated National Concept for Spatial Development, 2019, p.55). This conclusion undoubtedly justifies the formulation of goals and priorities, focused directly on more effective support of human capital and human resources management.

The integrated territorial strategies for developing the planning regions in the period 20212027 are strategic documents that define medium-term goals, priorities, and perspectives for 
sustainable integrated regional and local development on the territory of the respective planning region. These documents coordinate the sectoral strategies and documents at the regional level in economic development, health, education, science, social services, transport, water sector, energy, broadband communications, tourism, and environment and take into account their regional specifics and territorial dimensions.

The author's study showed that each integrated territorial strategy is directly related to activating and stimulating human capital development. The specifics and nuances arise from the peculiarities of the available demographic potential and needs of the respective territory population.

For example, in the highest economic and social development of the South-West Planning region, the priority orientation is towards "preservation and development of human capital by ensuring access to quality services" (Integrated Territorial Strategy for Development of the South-West Planning Region, 2020, p. 151).

The specific characteristics and significant differences between the areas in terms of human capital reproduction in the South-West region determine this priority's important role.

Improved quality and access to public services of paramount importance - health care, social services, active social inclusion of vulnerable groups, and effective implementation of the labor market lead to the preservation of regional demographic resources and improve the quality of life, social cohesion, and attractiveness for the residence of each territorial community. Highlights of the priority are:

- education and training for a highly qualified workforce,

- promotion of employment,

- ensuring equal access to quality health services,

- improving social services and social inclusion,

- protection,

- development and promotion of cultural heritage,

- provision of quality public services.

In contrast to the South-West region is the least developed North-West Planning region. However, the priority supporting the improvement of human resources is present by defining "preservation and development of human capital" (Integrated Territorial Strategy for Development of the North-West Planning Region, 2020, p.136). This priority is fundamental for the North-West region, which is characterized by some of the most unfavorable demographic trends and migration processes, and characteristics of human capital. Wellplanned investments in human resources are a powerful stimulator of growth, becoming increasingly important in national policy. The concentration of policies, activities, and measures for implementing this goal in the field of human resources development is justified by the need to address the identified, persistent problems in demographic and social development, which put the region at a disadvantage compared to other regions in the country. The priority activities are oriented towards expanding the access to quality education; achieving greater flexibility of the education system in response to changes in the labor market; creating conditions for quality employment, guaranteeing social inclusion; construction of adequate infrastructure for education and healthcare, sports, and cultural infrastructure; ensuring better health and cultural status of the population and improving social inclusion.

The focus of the second priority of the Integrated Territorial Strategy for Development of the North Central Planning Region is placed on developing human resources as the most 
important for the vitality and prosperity of the region. The emphasis is twofold: "development of human potential and achievement of social growth" (Integrated Territorial Strategy for Development of the North Central Region, 2020, p.139). Significant problems for the region are the negative demographic processes, especially in certain parts of its territory, the educational characteristics of a significant part of the population, the degree of satisfaction of the social needs of the population, the presence of pronounced interregional and intraregional differences in the conditions for human resources development. The priority activities are oriented towards expanding the access to quality education; achieving greater flexibility of the education system in response to changes in the labor market; construction of adequate infrastructure for education and healthcare, sports and cultural infrastructure; ensuring better health and cultural status of the population and improving social inclusion.

The Integrated Territorial Strategy for the development of the North-East Planning Region states (2020, p.133) that "A key factor for the integrated development of the region is the preservation and optimal use of human potential by improving education, improving skills, ensuring equal access to quality health care and social services, and by raising the general cultural level, leading to the formation of an active, enterprising and well-educated civil society, with a clear vision and aware of its mission for the development of the region". This argument again justifies the formulation of a priority aimed at improving human capital and ensuring equal access to education, healthcare, social services, labor market, as well as improving the quality of public services of paramount importance - health care, social services, and effective implementation of the labor market.

The Integrated Territorial Strategy for Development of the South-East Planning Region (2020, p.153) also highlights a priority factor for the region's integrated development to improve the quality of human capital through improved education, health and social, cultural, and sports services. These pillars of regional prosperity are accompanied by increased attention to the territorial balance in their development and actions to improve the quality of the economic and social environment and the material living environment in the settlements and throughout the region.

The measures envisaged in this priority aim to lead to better educational outcomes for learners; reducing early school leaving and raising the educational level of the population; increasing employment, especially youth employment, respectively reducing unemployment; better health care and a healthier lifestyle; improved educational, qualification and health characteristics of the workforce; higher productivity; poverty reduction, meeting the cultural and spiritual needs of the population.

The overall goal of improving the quality of human capital has found its place in priorities given in The Integrated Territorial Strategy for Development of the South Central Planning Region (2020, p.139). Analyzes report problems with the shortage of qualified staff and entrepreneurial skills, which have different territorial intensities, as well as deficits in terms of the use of growth and competitiveness factors - research, technology and innovation, high value-added products, internationalization, and regional specialization according to the specifics of local potentials in the South Central region. To overcome these weaknesses to improve the quality of human potential, several specific goals can be identified, including good education, professional development and new knowledge; creating opportunities for professional employment; ensuring equal access to quality health services; equal access to specialized long-term care and social inclusion; support for local cultural centers and protection of cultural heritage; improved access to sports and sports services. 


\section{CONCLUSION}

The comparative analysis of the 6th Integrated Territorial Strategies for Development of each of the planning regions of Bulgaria allows to deduce several regularities:

Firstly, one of the most critical factors in terms of their role in economic growth is the high quality of human capital. Unfortunately, the analyses consider the presence of specific alarming trends in the development of human potential in the country's regions. Not only is its number declining, but there are severe deficits in educational characteristics and skills.

Secondly, the integrated territorial strategies for developing the planning regions address critical challenges related to the dynamics of global and regional processes and phenomena, which are the basis for the functioning of the respective region's natural and social system.

Thirdly, human capital's most essential characteristics that increase its efficiency are knowledge, qualifications, and professional skills. In various forms, they are subject to future interventions in all planning regions.

Fourthly, strengthening human capital and improving the quality of life lead to social cohesion and increase of the attractiveness for living in any territorial community.

\section{NOTE}

[1] The Territorial Classification adopted by Bulgaria introduces three-level zoning corresponding to the NUTS 1, NUTS 2 and NUTS 3 territorial units' requirements under Regulation (EC) No 176/2008. of 20th February 2008 amending Regulation (EU) No $1059 / 2003$ on the common classification of territorial units for statistics (NUTS- French origin: Nomenclature des unités territoriales statistiques) applied by EUROSTAT for the regions of the European Union. The 6th Planning Regions are NUTS 2 level territorial units.

\section{REFERENCES}

Botseva, D. (2019). Development of Human Resources in the new Demographic Reality Manifestation of Paradoxes, Regional Development and Cross-Border Cooperation, Paper presented at III International Scientific-Expert Conference, Pirot, December 2019, Book of Proceedings, pp.611-621.

Botseva, D., G. Tsolov \& E. Vasileva (2020). Improvement of the Business Environment for Development of Cultural Regions, Paper presented at XIV International Turkish Culture, Art and Protection of Cultural Heritage Symposium Art/ Activity "In Honour of 2020 UNESCO Bilge TONIUKUK Year”, Book of Proceedings, pp.178-184.

Chatleska, V. Z. (2018). Human Resource Management in the Centers for Development of the Planning Regions in the Republic of Macedonia, Paper presented at Fourth International Scientific Business Conference LIMEN 2018, Conference Proceedings, pp.279284.https://doi.org/10.31410/limen.2018.279

Hyuseinov, B. (2017), Razvitie na choveshkiya kapital - ikonomicheski efekti i pazarni aspekti. (Human capital development - economic effects and market aspects). Narodnostopanski arhiv (Economic Archive journal). Vol.1, pp.41-60.

Kazakov, At. (2010), CHoveshkiyat kapital: kontseptualna ramka i funktsionalna metodologiya (Human Capital: Conception Frame and Functional Methodology), Research Papers, Vol.1, UNWE, Publishing Complex, rr.7-52.

Mazelis S.L., K.I. Lavrenyuk, A.A. Krask, \& O.N. Zagudaeva (2018), A Conceptual Model of The Regional Human Capital Development. International Transaction Journal of 
Engineering, Management, \& Applied Sciences \& Technologies, Vol. 9 No.4, pp.477494, http://TuEngr.com

Nikolov, G. \& V. Lyubomirova. (2019) Building an Integrated Regional Approach in the new Programming Period 2021-2027, Regional Development and Cross-Border Cooperation, Paper presented at III International Scientific-Expert Conference, Pirot, December 2019, Book of Proceedings, pp.631-638.

Tanakov, N. \& M. Kazakova (2018). Impact of Human Resources on The Development of the Regions. Paper presented at II International Scientific Conference Regional development and cross-border cooperation, Pirot, Serbia, pp 513-521.

Schultz, T. W. (1961). Investment in Human Capital. American Economic Review, March, pp.1-17. https://drive.google.com/file/d/1g9xy_J5b5VbXMF-BwnkIctky9t66idhH/view

Ikonomikata na Balgariya i Evropeyskiya sayuz. Strategiya za dogonvashto ikonomichesko razvitie do 2020 godina (The economy of Bulgaria and the European Union. Strategy for catching up with economic development until 2020) (2003). Research project, leader I. Angelov, Institute of Economics, BAS, Sofia, Bulgaria. https://www.iki.bas.bg/english/CVita/angelov/prognosis2020/010Chapter08.htm

National Development Program: Bulgaria 2030. Council of Ministers of the Republic of Bulgaria, Sofia, 2019. http://www.strategy.bg/PublicConsultations/View.aspx?@lang=bg-BG\&Id=4682

Updated National Concept for Development of Bulgaria (2013-2025). Council of Ministers of the Republic of Bulgaria, 2019. http://www.strategy.bg/PublicConsultations/View.aspx?@lang=bg-BG\&Id=4894

Integrated Territorial Strategy for Development of the North-West Planning Region. National Center for Spatial Planning, Ministry of Regional Development and Public Works, Sofia, 2020. https://drive.google.com/file/d/1M3tuTtCD0Ylwf7-sapLQovrMlFPE71TH/view

Integrated Territorial Strategy for Development of the North Central Planning Region. National Center for Spatial Planning, Ministry of Regional Development and Public Works, Sofia, 2020. https://drive.google.com/file/d/1hd73EjaZP9wZCnNsjjBT9LngpYAQlij0/view

Integrated Territorial Strategy for Development of the North-East Planning Region. National Center for Spatial Planning, Ministry of Regional Development and Public Works, Sofia, 2020. https://drive.google.com/file/d/1uZcGgz7lnPe-dRcc7REEk3sVVkbHDcYd/view Integrated Territorial Strategy for Development of the South-East Planning Region. National Center for Spatial Planning, Ministry of Regional Development and Public Works, Sofia, 2020.

https://drive.google.com/file/d/1PQHitXvH1w5HJ1GzUcQid0gLqGwOgYMM/view

Integrated Territorial Strategy for Development of the South Central Planning Region. National Center for Spatial Planning, Ministry of Regional Development and Public Works, Sofia, 2020. https://drive.google.com/file/d/1Zs0ByPWioPaXx_HmIRWXuQJpcGReGhEP/view Integrated Territorial Strategy for Development of the South-West Planning Region. National Center for Spatial Planning, Ministry of Regional Development and Public Works, Sofia, 2020. https://drive.google.com/file/d/1lxDLrdvhhfrngi5FikAB1ua03D--QZuT/view 